\title{
ASPHYXIA NEONATORUM DUE TO A NASOPHARYNGEAL TERATOMA
}

\author{
BY \\ C. W. KESSON \\ From St. George's Hospital, London
}

(RECEIVED FOR PUBLICATION DECEMBER 29, 1953)

Although a nasopharyngeal teratoma occurs but rarely, it may be a cause of acute asphyxia in the newborn baby. The tumour is often readily amenable to surgical removal.

Ehrich (1945) gives a comprehensive survey of the literature relating to teratoid parasites of the mouth. He refers to the earlier publications of Ahlfeld (1875), Arnold (1888) and Schwalbe (1907) and discusses their theories relating to the pathogenesis of such tumours. Ahlfeld believed they were all twin formations. Arnold classified them according to their state of development and agreed that the highly developed variety were true double monsters but believed the more simple type, the so-called hairy polyp, was a tissue malformation due to cell dislocation early in development. Schwalbe favoured a similar classification but considered that all had an identical pathogenesis and were caused by dislocation of germ material. The earlier in development this occurred the more complex was the resulting tumour. At the present time the pathogenesis of teratoma formation is based on the organizer theory of Spemann. Needham (1942) compares naturally occurring and experimentally induced teratomata and concludes that the malformations are only explicable as the result of uncoordinated organizer action. Not only must the liberation of evocator (stimulus) at times and places where it is not normally liberated be considered, but also competence to respond to evocator beyond the time at which it is normally lost. He concludes by stating that primary evocator is present in most adult tissues of animals in the free state and it is therefore likely that prolongation of the period of competence is a more important factor. It is evident that from them both, by all sorts of combinations and permutations, everything that we know of under the name of the teratomata may be produced.

The present report is concerned with the simple type of teratoma or hairy polyp. Ehrich (1945) refers to 79 similar cases and references to 11 more have been found in the literature since that time.

\section{Case Report}

D.H. was born on July 3, 1952, the fourth child of a healthy mother. The pregnancy and labour were normal and the birth weight of the infant was $6 \mathrm{lb} .13 \frac{1}{2} \mathrm{oz}$. Immediately after delivery a little mucus was removed from the nose and mouth but no significant departure from the normal was noticed.

Three hours later the child suddenly became cyanosed and dyspnoeic. On examination, within a few minutes of the onset of these manifestations, the infant was found to be almost black and there was marked respiratory distress with retraction of the tissues in the submandibular region, suprasternal area and lower part of the chest wall at each attempt at inspiration. The air entry of the lungs was greatly diminished and generalized moist sounds were heard. The mouth was normal but a yellow mass could be seen in the oro-pharynx. As the baby gagged a sausage-shaped tumour was brought forward into the buccal cavity pulling the soft palate anteriorly.

A rubber catheter was passed through the mouth beyond the nasopharyngeal tumour into the pharynx and this immediately provided an efficient airway. Then without anaesthesia the pedicle of the mass was snared and the tumour removed whole. Although the relief from respiratory embarrassment was immediate, clinical evidence of lung atelectasis persisted for a further $\mathbf{4 8}$ hours. During this time the baby was nursed in an oxygen tent in the head-down position. A chest radiograph taken on the seventh day of life showed that the lung fields were normal. There was no delay in the establishment of breast feeding and the birth weight had been regained when the infant was discharged from hospital on the fourteenth day of life. A report from the patient's doctor confirms that the child is in good health at the age of 1 year.

A photograph of the teratoma is shown in Fig. 1. The following report on the histology was given by Dr. Gowing:

The specimen is an ovoid nodule measuring $2 \times 1 \times 1$ $\mathrm{cm}$. It is apparently covered by skin and there is a narrow pedicle. Examination of the cut surface shows the centre of the nodule to be occupied largely by adipose 
tissue. Microscopically there is a small nodule of cartilage at the centre and surrounding this is a broad layer of adipose tissue. The exterior of the nodule is covered by skin which shows well marked keratinization and numerous pilo-sebaceous follicles. The nodule is clearly a congenital malformation and there is no evidence of true neoplasia.

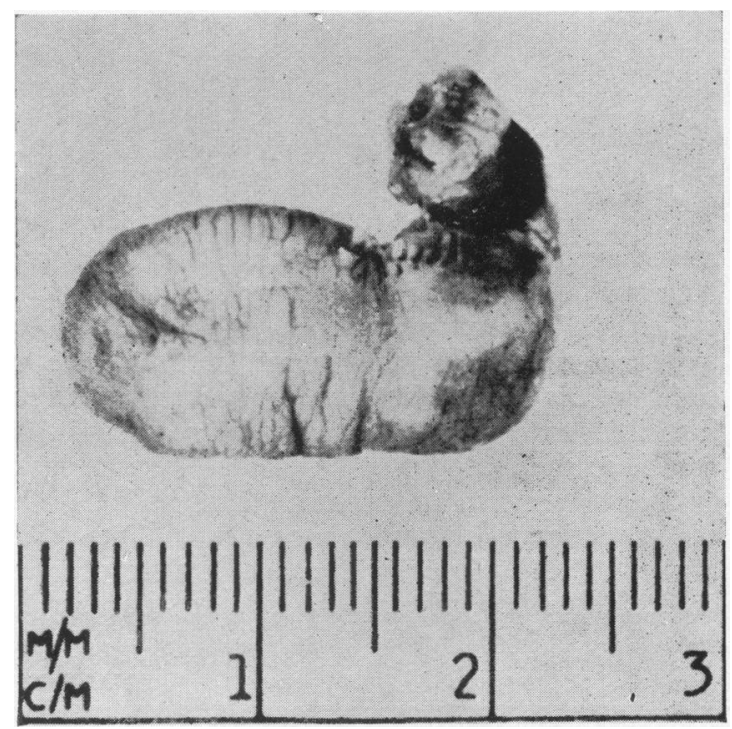

FIG. 1.-Macroscopic appearance of the excised tumour.

\section{Comment}

This child was simply and effectively treated surgically within six hours of birth. In the last 20 years six other cases have been recorded where surgical removal of a hairy polyp has been successfully conducted during the neonatal period (Stokoe, 1937; Foster, 1944; Sjövall, 1951; Sala, 1951;
Frenkel, 1951; Bodian and White, 1952). The more highly developed teratoma usually occur in stillborn babies but Ochsner and Ayers (1951) describe such a tumour which was removed on the fourth day of life after a preliminary tracheotomy and gastrostomy.

It is interesting that our patient's elder sister, who was one of twins, was admitted to the Victoria Hospital for Children at the age of 20 months with an abdominal tumour. This was a pararenal neoplasm which showed patchy calcification radiologically, and was considered to be a neuroblastoma or teratoma. Laparotomy was performed but the mass was firmly adherent to the vena cava preventing its removal, and its vascularity made biopsy inadvisable. This child is now $4 \frac{1}{2}$ years of age and has remained in good health. Although the nature of her neoplasm is so far unproved it is very likely to be a teratoma.

\section{Summary}

A case of nasopharyngeal teratoma causing acute asphyxia neonatorum is described. The tumour was successfully removed in the neonatal period.

It is a pleasure to express my indebtedness to $\mathrm{Mr}$. Pereira who operated on this child so successfully. I am grateful to Dr. Ursula James and Mr. Rodney Smith for allowing me access to the case notes of the elder sister.

Ahlfeld, F. (1875). Arch. Gynaek., 7, 210. Arnold, J. (1888). Virchows Arch., 111, 176

Bodian, M. and White, L. L. R. (1952). Gt Ormond Str. J., 2 (No. 4), 105.

Ehrich, W. E. (1945). Oral Surg., 31, 650

Foster, J. H. (1944). Ann. Otol., St. Louis, 53, 578

Frenkel, M. M. (1951). Vestn. Oto-rino-laring, 13 (No. 3), 68.

Needham, J. (1942). Biochemistry and Morphogenesis. Cambridge. Ochsner, A. and Ayers, W. B. (1951). Surgery, 30, 560.

Sala, O. (1951). Boll. Mal. Orecch., 69, 112.

Schwalbe, E. (1907). Die Morphologie der Missbildungen, Vol. 2. Jena.

Sjövall, A. (1951). Nord. Med., 46, 1531.

Stokoe, J. (1937). Brit. med. J., 2909. 